\title{
Contagion and Cognition: Bodily Experience and the Conceptualization of Pollution (tum'ab) in the Hebrew Bible
}

\author{
YITZHAQ Feder, University of Haifa *
}

\section{Introduction}

Abnormal genital discharges, corpses and creeping things-confronting these unpleasant realities in the Priestly purity regulations of the Hebrew Bible (e.g., Leviticus 11-15; Numbers 19) is too much for many people, scholars included, to stomach. Nevertheless, a brave few have attempted to find some redeeming value in this corpus by deciphering the meanings concealed within this systematic code. Despite their efforts to uncover a discourse on abstract social or theological categories, the gruesome details of these stipulations are not particularly hospitable to interpretations that are rooted in an abstract, disembodied mode of rationality.

One need not deny, however, that these laws are logical. On the contrary, the project of this article is to elucidate the pervasive logic of these laws as an expression of embodied rationality. By emphasizing the grounding of language and thought in bodily experience (through reference to modern "embodiment theory"), I will venture to provide a more satisfying account of the biblical concept of "pollution" $\left(t u m^{\prime} a h\right)$ as based on several distinct images or models by which this notion was conceptualized in ancient Israel.
To a certain extent, this line of inquiry was initiated by Paul Ricoeur's study The Symbolism of Evil, which sought to trace changing conceptions of evil in the Western tradition back to their ancient Israelite and Greek origins. Starting from the principle "the symbol gives rise to thought," Ricoeur recognized the indispensable role of concrete images in the articulation of religious intuitions. ${ }^{1}$ Put simply, Ricoeur's investigation was based on the realization that religious experience is mediated by symbols, and accordingly, that an analysis of symbols can reveal a history of earlier conceptions. Unfortunately, this important first step

\footnotetext{
* The research for the paper was conducted during a fellowship at the W. F. Albright Institute of Archaeological Research. I thank Edward Greenstein, Michael Kimmel, and the editors of JNES, especially Seth Richardson, for helping me improve the arguments in this article and their presentation. This study was selected for the Society of Biblical Literature's 2012 David Noel Freedman Award and was presented at a panel discussion at the SBL Annual Meeting in November 2012. I am grateful to the participants in the panel, Elizabeth Bloch-Smith, Jonathan Klawans and Edward Slingerland for their insightful comments. The abbreviations used follow the Society of Biblical Literature (SBL) Handbook of Style, ed. P. H. Alexander et al. (Peabody, MA, 1999).

${ }^{1}$ P. Ricoeur, The Symbolism of Evil, trans. E. Buchanan (New York, 1967), 347-48.
} 
in tracing the origins of the biblical notion of pollution was largely ignored by subsequent research, probably due to the impenetrability of Ricoeur's work. ${ }^{2}$

The present study will explore the relationship between pollution and the experiences of uncleanness and disease. Although the similarity of purity regulations to hygienic practices and fear of infection is obvious, it has yet to be adequately explained. In fact, due to the recognition that pollution cannot be simply reduced to a concern for bodily cleanliness and health, this relationship has often been dismissed categorically. In my view, this rejection is overhasty, based on faulty methodological premises.

My discussion will be divided into four sections. The first section focuses on the theoretical background for attempts to interpret pollution, emphasizing the distinction between the abstract rationality implicit in symbolic interpretations and the notion of embodied rationality advocated here. The second section seeks to establish the plausibility of the assertion that several types of pollution were originally viewed as infection, with special attention given to evidence from Mari in ancient Mesopotamia. The aim here is to provide an appropriate context for analyzing ancient notions of disease and their relation to the biblical notion of pollution. The third section builds upon the methodological and historical considerations of the previous sections in order to elucidate biblical texts in which a relationship between pollution and infection is suggested, specifically Leviticus 15 (genital discharges), Numbers 19 (corpse pollution) and Leviticus 13-14 (skin disease). The fourth and final section explores the logic underlying the conceptualization of pollution, elucidating the psychological mechanism by which this unseen force was modeled after phenomenal experience.

\footnotetext{
${ }^{2}$ The substance of Ricoeur's analysis is also problematic, specifically its attempt to incorporate "defilement" together with "sin" and "guilt" into a single linear scheme of changing conceptions of evil. Most recent studies endorse a more descriptive approach. See e.g., T. Frymer-Kensky, "Pollution, Purification and Purgation in Biblical Israel," in The Word of the Lord Shall Go Forth: Essays in Honor of David Noel Freedman in Celebration of his Sixtieth Birthday, ed. C. L. Meyers and M. O'Connor (Winona Lake, IN, 1983), 399-414; D. P. Wright, "Clean and Unclean," $A B D$ VI, 729-41; ibid., "The Spectrum of Priestly Impurity" in Priesthood and Cult in Ancient Israel, ed. G. A. Anderson and S. M. Olyan, JSOTSup 125 (Sheffield, 1991), 150-81; S. M. Olyan, Rites and Rank: Hierarchy in Biblical Representations of Cult (Princeton, 2000), 38-62.
}

\section{Pollution and Rationality}

\section{Pollution as Abstract Rationality: The} Search for a Unifying Logic

One of the challenges of studying tum'ah is the fact that this concept is neither wholly concrete nor abstract. Though some scholars have suggested that the term may be etymologically derived from the senses of "dirt" or "mud," 3 the Bible does not attest these usages. Ricoeur notes: "Defilement is not a stain, but like a stain; it is a symbolic stain." ${ }^{4}$ But since the label "symbolic" obscures as much as it reveals, the questions remain: how did this peculiar metaphysical concept originate, and why was it treated with such utter seriousness?

A further source of ambiguity is the heterogeneous usage of tum'ah in the Bible, a diversity that is not easily organized into a unitary logical scheme. Blurring the domains of hygiene and morality, and encompassing disparate situations such as genital emissions (normal and abnormal), corpses, bloodshed, sexual misconduct and idolatry, this term seems to resist systematic analysis. In reality, however, the main obstacle that stands in the way of making sense of this category is a lexicographic predisposition towards abstract, disembodied logic, particularly the assumption that linguistic categories are defined by necessary and sufficient membership criteria.

This latter approach, which guides innumerable studies in biblical semantics until this day, can be traced back at least to Aristotle. However, as pointed out by Ludwig Wittgenstein, the inadequacy of this approach becomes apparent when confronted with categories such as "games" (e.g., baseball, solitaire, ring-around-the-rosie) that cannot be reduced to a set of fixed characteristics. In the case of "games," characteristics such as amusement and competition do not apply to all cases. ${ }^{5}$ One may argue that these games share some common characteristics (e.g., they have

\footnotetext{
${ }^{3}$ W. Paschen, Rein und Unrein: Untersuchung zur biblischen Wortgeschichte (München, 1970), 27. The main basis of this view is the purported cognate tamy in Egyptian Arabic with the sense "silt of the Nile." See also G. André,"טמא," TDOT 5:330-31; HALOT: 375.

${ }^{4}$ Ricoeur, Symbolism of Evil, 36. This observation may also apply to the Old Southern Arabic evidence. See J. Ryckmans, "Les confessions publiques sabéennes: le code sud-arabe de purité rituelle," AION 22 (1972): 5, n. 21.

${ }^{5}$ Ludwig Wittgenstein, Philosophical Investigations, trans. G. E. M. Anscombe (Oxford, 1963), 31-32 (\$66).
} 
rules), but these are insufficient, taken by themselves, for inclusion in the category. ${ }^{6}$

Such considerations have led to the emergence of alternative theories which emphasize the role of family resemblances and prototypes in shaping the semantic development of languages. ${ }^{7}$ These modern approaches are more consistent with the recognition that languages develop through localized innovations (through principles of association such as metonymy and analogy) which need not conform to any single rigid propositional logic. ${ }^{8}$ Whereas the classical approach expects linguistic categories to be homogeneous, governed by a pervasive and comprehensive order (criteria of inclusion and exclusion), modern approaches recognize that many linguistic categories are heterogeneous, structured around several distinct prototypical examples. In short, one can distinguish between a "top-down" model of semantics, whereby the lexicon of a given language is governed by rules dictated by the rational mind, and a "bottom-up" model whereby the linguistic system is the result of countless localized instances of semantic development. While the former model may serve as the ideal for a formal language (an artificial language created for the sake of mathematics, computer programming, philosophical inquiry, etc.), only the latter model is appropriate for a natural language. ${ }^{9}$

With respect to these considerations, the heterogeneous content of the biblical category of pollution is hardly exceptional. What is necessary to make sense of the different types of tum'ah and their characteristics is a proper appreciation of experiential images or models upon which they are based. In employing the term "image," I am referring to schematized

\footnotetext{
${ }^{6}$ See P. Violi, Meaning and Experience, trans. J. Carden (Bloomington, 2001), 152-54.

${ }^{7}$ For a more detailed overview, see G. Lakoff, Woman, Fire and Dangerous Things: What Categories Reveal about the Mind (Chicago, 1987), 5-154, with special attention given to the pioneering work of Eleanor Rosch.

${ }^{8}$ See e.g., A. Blank, Prinzipien des lexikalischen Bedeutungswandels am Beispiel der romanischen Sprachen (Tübingen, 1997); E. C. Traugott and R. B. Dasher, Regularity in Semantic Change (New York, 2001).

${ }^{9}$ Generally, the aim of creating formal languages is to eliminate ambiguity by attributing a univalent definition to each term. A notable example would be the attempt to establish an ideal philosophical language, pursued by Bertrand Russell and Wittgenstein in the early twentieth century, though ultimately Wittgenstein abandoned this line of inquiry to delve into the complexities of natural language.
}

understandings of recurrent bodily experiences (not necessarily visual), which can be simple or complex. ${ }^{10}$ Not only will this approach provide a more accurate understanding of the lexical data, it will offer a key to the exegesis of the purity laws.

So far I have discussed the rationality of semantic categories as it pertains to the concept of tum'ah. A similar tendency to assume a coherent rational structure also finds expression in the analysis of pollutionrelated practices. Whether based in the symbolist tradition of Émile Durkheim or the structuralist tradition of Claude Lévi-Strauss, these analyses tend to assume an underlying logical scheme, whereby the practices represent either social or cognitive categories.

Though attempts to understand this concept allegorically can be traced back to late antiquity, the modern tendency to interpret purity regulations as a symbolic system is largely indebted to the influential work of Mary Douglas. Starting from the premise that dirt is "matter out of place," she shows the potential for using impurity customs and beliefs as keys to deciphering the symbolic system of the culture:

Dirt then, is never a unique, isolated event. Where there is dirt, there is system. Dirt is the by-product of a systematic ordering and classification of matter, in so far as ordering involves rejecting inappropriate elements. This idea of dirt takes us straight into the field of symbolism and promises a link-up with more obviously symbolic systems of purity. ${ }^{11}$

According to this framework, before one can account for why a given act is defiling, one must first identify the classificatory system that is being violated. In this manner, Douglas argued that the designation of unclean animals in Leviticus 11 and Deuteronomy 14 stems from their anomalous characteristics (e.g., aquatic creatures lacking fins and scales). These deviations caused them to be perceived as threatening the

${ }^{10}$ This usage is largely compatible with M. Kimmel's characterization of "image schemas." It is important to keep in mind that the pollution schema is primarily a pattern of active response, not a mental representation. See M. Kimmel, "Culture Regained: Situated and Compound Image Schemas," in From Perception to Meaning: Image Schemas in Cognitive Linguistics, ed. B. Hampe (Berlin, 2005), 285-312; and "Properties of Cultural Embodiment: Lessons from the Anthropology of the Body," in Body, Language and Mind. Volume 2: Sociocultural Situatedness, ed. R. M. Frank et al. (Berlin, 2008), 77-108.

${ }^{11}$ Mary Douglas, Purity and Danger: An Analysis of the Concepts of Pollution and Taboo (London, 1992 [1966]), 35. 
biblical notion of holiness, equated with wholenessof the individual and the category.

This approach has been refined and adapted in subsequent studies, including those of Douglas herself, and its working assumption continues to inspire research. In particular, biblical scholars have enthusiastically developed the premise that the body can serve as a medium of expression onto which social ideals and patterns are projected. For example, Howard EilbergSchwartz writes: "The fluids of the body turn out to be a kind of language in which various religious themes find their voice." ${ }^{12}$ Even more forcefully, Jon Berquist views the laws of bodily fluids as implying an aspiration for bodily wholeness, itself a microcosm for the ideal Israelite society:

The whole body, for Israel, was not only a construction of how culture expected the physical body to operate and perform; the body was also a representation of how the society should organize itself and function, in the smallest units (the family or household) as well as the largest (the tribe, the nation, the colony, or any other form of the "body politic"). ${ }^{13}$

With all due respect for the ingenuity required for such homologies, these studies raise several difficulties. For instance, assuming that these symbolic interpretations were external to the conscious motives of the ancient Israelites observing various ritual practices, these studies fail to explain by what mechanism these symbolic schemes (unconsciously) emerged. Furthermore, these interpretations assume a questionable mind-body dualism in which the body serves as a vehicle of expression which can effectively be disre-

${ }^{12} \mathrm{H}$. Eilberg-Schwartz, The Savage in Judaism: An Anthropology of Israelite Religion and Ancient Judaism (Bloomington, 1990), 179.

${ }^{13}$ J. L. Berquist, Controlling Corporeality: The Body and the Household in Ancient Israel (Piscataway, 2002), 45. This view takes its inspiration from Douglas' assertion: "The threatened boundaries of [the Israelites'] body politic would be well mirrored in their care for the integrity, unity, and purity of the physical body" (Purity and Danger, 124). However, it should be noted that Douglas later retracted this statement in light of the fact that Leviticus and Numbers do not employ these rules to separate Israelites from foreign races (In the Wilderness: The Doctrine of Defilement in the Book of Numbers [Sheffield, 1993], 20). More recently, she has argued for a homology between the body and the hierarchy of sacred space in the Tabernacle (Leviticus as Literature [Oxford, 1999], 190-91), a view already proposed in R. Whitekettle, "Leviticus 15.8 Reconsidered: Chiasm, Spatial Structure and the Body," JSOT 49 (1991): $31-45$. garded once the encoded message is comprehended. ${ }^{14}$ While authors disagree as to how to interpret the hidden logic of the "purity system," 15 they rarely address the possibility that the project itself is fundamentally ill-conceived. ${ }^{16}$

For example, a common view which finds expression among traditional and modern exegetes alike is that impurity symbolizes death. ${ }^{17}$ Proponents of this theory point to the explicit connections between the skin disease sara'at (conventionally translated "leprosy") and references to death (Numbers 12:12) and mourning (Leviticus 13:45-46). These scholars also construe menstrual impurity (Leviticus 15:19-24) as stemming from the loss of life-fluid and for constituting a period of infertility. Unfortunately, this view is ill-equipped to explain why sexual relations defile (Leviticus 15:18), ${ }^{18}$ notwithstanding the counter-intuitive claim that the loss of seed (even in coitus) is a kind of death. ${ }^{19}$ These theories suffer from the endemic weakness of Aristotle's theory of categorization: any exceptional case undermines the assumption that category membership is defined by fixed criteria.

An alternative approach has been to explain the impure discharges as a result of their uncontrollable nature. For example, to explain the biblical distinction between the minor impurity of semen from other

${ }^{14}$ See M. Jackson, Paths toward a Clearing: Radical Empiricism and Ethnographic Inquiry (Bloomingfield, 1989), 122-23.

${ }^{15}$ For an insightful survey, see C. Nihan, From Priestly Torah to Pentateuch, FAT2/25 (Tübingen, 2007), 301-39.

${ }^{16}$ See, however, Walter Houston's extensive critique of Douglas' view as it bears on the dietary laws (Purity and Monotheism: Clean and Unclean Animals in Biblical Law, JSOTSup 140 [Sheffield, 1993], 93-123), and more comprehensively T. M. Lemos, "Where There Is Dirt, Is There System?: Revisiting Biblical Purity Constructions," JSOT 37 (2013): 265-94.

${ }^{17}$ This interpretation has been advanced forcefully by J. Milgrom, Leviticus 1-16 (New York, 1991), 766-68; 1000-1003. See also Olyan, Rites and Rank, 143-44, n. 15; Nihan, From Priestly Torah, 304, n. 158.

${ }^{18}$ Nor can this "anomaly" be swept under the rug, since it appears consistently cross-culturally. See, e.g., R. Parker, Miasma: Pollution and Purification in Early Greek Religion (Oxford, 1983), 74; K. van der Toorn, Sin and Sanction in Israel and Mesopotamia: A Comparative Study (Assen, 1985), 22.

${ }^{19}$ See, e.g., G. J. Wenham, "Why Does Sexual Intercourse Defile (Lev 15 18)?" ZAW 95 (1983): 432-34; E. L. Greenstein, "Biblical Law," in Back to the Sources: Reading the Classic Jewish Texts, ed. B. W. Holz (New York, 1984), 95, who coins the expression "lifeleaks." However, as H. Maccoby points out, these approaches are undermined by the fact that the life-threatening loss of blood from an open wound is not defiling (Ritual and Morality: The Ritual Purity System and its Place in Ancient Judaism [Cambridge, 1999], 49). 
genital discharges, H. Eilberg-Schwartz argues: "Since semen is ejaculated from the body through orgasm, its loss is symbolically associated with direct action and conscious thought. Nonseminal discharge and menstrual blood, on the other hand, are passively released from the body." ${ }^{20}$ But this theory is hard-pressed to explain why the impurity of a deliberate sexual act is the same as that of an accidental seminal emission (Leviticus 15:16). ${ }^{21}$ Upon reading these attempts, one is struck by the intense efforts expended to derive the concrete rules pertaining to bodily conditions from abstract categories. When the originally-proposed dichotomies (life/death, control/lack of control) fail to fit the data, further distinctions are added-male versus female, upper versus lower orifices, etc.-with the aim of preserving the abstract category distinctions. ${ }^{22}$ If adding more detailed parameters based in embodied experience contributes to a better understanding of the data, perhaps we should consider the possibility that the logic is embodied through and through and unrelated to abstract schemes. Or perhaps this can be formulated as a question: should a correct interpretation be based on an abstract explanation which sees beyond the textual details which focus on bodily experience, or should the explanation emerge from an engagement with the "grisly details" of bodily experience?

\section{Pollution as Embodied Rationality}

I have hinted above at the possibility that the semantics of the term tum'ah and the practices associated with this concept may be better explained as an expression of a "bottom-up" (situated and embodied) mode of rationality. In seeking a theoretical framework for this alternative account, we can benefit from the intense collaboration in recent decades of cognitive scientists, philosophers, anthropologists and semioticians in the development of theories of embodied cognition.

\footnotetext{
${ }^{20}$ Eilberg-Schwartz, The Savage in Judaism, 186-89, esp. 187.

${ }^{21} \mathrm{M}$. Malul, who substitutes his notion of "epistemic control," is still unable to offer a satisfactory explanation (Knowledge, Control and Sex. Studies in Biblical Thought, Culture and Worldview [TelAviv, 2002], 387-90).

${ }^{22}$ Ibid., 386-94. These efforts are reminiscent of attempts to create a disembodied Artificial Intelligence by means of abstract rules and propositions, despite the fact that human intelligence is situated and embodied. See H. L. Dreyfus, What Computers Still Can't Do: A Critique of Artificial Reason (Cambridge, MA, 1992); A. Clark, Being There: Putting Brain, Body and World Together Again (Cambridge, MA, 1997).
}

Though this field of research is hardly monolithic, many of its advocates share a concern with the role of the phenomenological experience of living in a body on the processes of reasoning. In referring to embodiment in the present context, I wish to demonstrate that the ancient Israelite conception of pollution was grounded in concrete experience and should be analyzed from a phenomenological perspective that is philosophically non-dualistic, socio-culturally situated and appeals to the emotion-laden subjectivity of individual actors. ${ }^{23}$

Let us begin with an anthropological account of pollution which encapsulates many of the emphases of embodiment theory. In an important critique of Douglas' theory based on field work in Papua New Guinea, A. S. Meigs points out that not every disordered phenomenon is considered defiling. Whereas a toy boat on the kitchen table may be "messy," it is not considered defiling like shoes on the kitchen table. The reason for this discrepancy, Meigs suggests, is that shoes are potential carriers of substances such as feces, urine and saliva from the street. More generally, she relates notions of defilement to a visceral sense of disgust for decay and waste matter, particularly when these threaten to access another person's body, such as through eating or sexual relations. ${ }^{24}$ For our purposes, the important point is the difference between Meigs's emotional/intuitive account of defilement and that of Douglas and others who relate the notion to category violations or ambivalent states. Unlike the abstract explanations of pollution which invoke goals foreign to the motives of the actors, Meigs's account is consistent with their conscious concerns. ${ }^{25}$

As the work of Meigs suggests, one need not travel to Papua New Guinea in order to study pollution, as this notion finds parallels much closer to home. In a large-scale research program spanning decades, Carol Nemeroff and Paul Rozin have examined the notion of contagion, particularly as experienced by academically-educated Americans. In a general formulation, they describe contagion as the assumption that "physical contact between the source and the target

\footnotetext{
${ }^{23}$ For a comprehensive meta-theoretical framework encompassing the various approaches, see T. Rohrer's helpful list of "dimensions of embodiment" in "The Body in Space: Dimensions of Embodiment," in Body, Language and Mind. Volume 1: Embodiment, ed. T. Ziemke et al. (Berlin, 2007), 348-59.

${ }^{24}$ A. S. Meigs, "A Papuan Perspective on Pollution," Man 13 (1978): 304-18.

${ }^{25}$ See ibid, 317, n. 9.
} 
results in the transfer of some effect or quality (essence) from the source to the target." ${ }^{26}$ In some cases, the assumption of a transfer of essence is corroborated by science (e.g., in germ-theory), but frequently it is based on an emotional bias that overwhelms cold reason. As a simple illustration, a person who picks up a piece of feces or cockroach by means of a plastic bag is usually inclined to wash his hands afterwards, despite the absence of actual contact.

The modes of transfer involved in schemas of contagion are modeled after those perceived in phenomenological experience. Among the numerous experiments carried out by Nemeroff and Rozin, a particularly relevant study was their inquiry into mental models associated with contagion, first published in $1994 .{ }^{27}$ This study was based on interviews and questionnaires given to adult Americans who were asked about their reaction to wearing a sweater after it had been in contact with various types of negative influence. Participants were also questioned whether they felt certain "purificatory" procedures could undo the negative effects of contagion. In analyzing these responses, Nemeroff and Rozin detected a clear distinction between physical and nonphysical models of contagion.

The physical model of contagion included sources such as feces and disease, most of which could be "purified" by means of acts such as washing and boiling the sweater. The nonphysical model, by contrast, applied to moral and social sources, i.e., a sweater worn by an enemy or mass-murderer, which could be best "purified" by exposure to an opposing valence (i.e., being worn by a person with positive social or moral attributes). Granted, responses would often blur the distinction between physical and nonphysical sources of contagion. Nevertheless, the results of this study clearly support the conclusion that contagion schemas operate according to ontological assumptions regarding the nature of the essence transmitted within

${ }^{26}$ C. Nemeroff and P. Rozin, "The Makings of the Magical Mind: The Nature and Function of Sympathetic Magical Thinking," in Imagining the Impossible: Magical, Scientific and Religious Thinking in Children, ed. K. S. Rosengren et al. (Cambridge, 2000), 3.

${ }^{27}$ C. Nemeroff and P. Rozin, "The Contagion Concept in Adult Thinking in the United States: Transmission of Germs and Interpersonal Influence," Ethos 22 (1994): 158-86, and "Sympathetic Magical Thinking: The Contagion and Similarity 'Heuristics,"” in Heuristics and Biases: The Psychology of Intuitive Judgment, ed. T. Gilovich et al. (Cambridge, 2002), 211-13. The following summary is necessarily much abbreviated; the reader should consult the original publication for further details. the framework of accepted cultural beliefs, though, when questioned, respondents would admit (with embarrassment) that their responses were not entirely consistent with purely scientific reasoning.

\section{Defilement and Disease: Regaining a Historical Perspective}

Since the emotional responses to contagion are dependent on culturally legitimated attitudes, it is worthwhile to examine the relationship between pollution and ancient perceptions of disease. Despite the common recognition of the similarity between practices motivated by hygiene and those pertaining to 'ritual purity', the relationship between these two categories of behavior has yet to receive an adequate explanation. In the late nineteenth century, E. B. Taylor characterized ritual purification as representing "the transition from practical to symbolic cleansing, from removal of bodily impurity to deliverance from invisible, spiritual, and at last moral evil." 28 However, the historical data do not corroborate this neat linear account. A different type of evolutionary explanation is suggested by evolutionary psychologists who point out that this disgust response is remarkably well-adapted for distancing humans from disease, parasites and other sources of danger. ${ }^{29}$ However, in their emphasis on biological selection pressures, these accounts do not adequately address the actual motives governing the conscious behavior of actors. ${ }^{30}$

${ }^{28}$ E. B. Taylor, Religion in Primitive Culture (New York, 1958 [1873]), 515 .

${ }^{29}$ See e.g., C. D. Navarrete and D. M. T. Fessler, "Disease Avoidance and Ethnocentrism: The Effects of Disease Vulnerability and Disgust Sensitivity on Intergroup Attitudes," Evolution and Human Behavior 30 (2006): 270-82; M. Oaten, R. J. Stevenson, and T. I. Case, "Disgust as a Disease-Avoidance Mechanism," Psychological Bulletin 135 (2009): 303-21; P. Prokop and J. Fančovičova, "The Association Between Disgust, Danger, and Fear of Macroparasites and Human Behaviour," Acta Ethologica 13 (2010): 57-62. For an application of an evolutionary perspective to the biblical notion of pollution, see T. Kazen's "Dirt and Disgust: Body and Morality in Biblical Purity Laws," in Perspectives on Purity and Purification in the Bible, ed. B. S. Schwartz et al. (New York, 2008), 43-64, and "Impurity, Ritual, and Emotion: A Psycho-Biological Approach," in Issues of Impurity in Early Judaism (Winona Lake, IN, 2010), 13-40. These approaches provide a coherent and convincing alternative to the groping attempt of W. I. Miller to characterize disgust in The Anatomy of Disgust (Cambridge, MA, 1997), 38-108.

${ }^{30}$ As Houston remarks regarding cultural materialism, one must still explain "the mechanism by which an ecological need becomes a religious prescription" (Purity and Monotheism, 92). 
More commonly, a direct relationship between hygiene and purity is dismissed out of hand by modern scholars. Though this point is usually discussed in relation to the dietary laws (Leviticus 11), the points raised are illuminating examples of how logical nonsequiturs can close off potentially fruitful lines of inquiry. When the biblical rules are consistent with medical knowledge, e.g., the relationship between trichinosis and uncooked pork, the question raised is how the Israelites could have known. When scientific data contradict the rules, that is taken as even stronger grounds for rejecting a hygienic rationale. ${ }^{31}$ Most forcefully, the medieval rabbinic commentator Abravanel points out that there is no evidence that Jews were healthier than gentiles, thus dismissing the assumption of health as a basis for the dietary laws. ${ }^{32}$

Since the anachronism implicit in these arguments is seldom recognized, it is necessary to begin our discussion with a historical survey of models of infection in order to establish a more fitting interpretive context by which to understand the biblical evidence. ${ }^{33}$ Premodern conceptions of infectious diseases are invariably structured by metaphors. ${ }^{34}$ Nutton writes: "It is important first to remember that in all this we are dealing with descriptions of the invisible, with hypothetical reconstructions of how things are or act, based only on the observance of "macrophenomena."” $35 \mathrm{Al}$ though Galen's references to "seeds of disease" in the second century C.E. may have prefigured germ theory to some degree, this potential was left virtually unexplored for the next 1,600 years. In the meantime, Western medicine was dominated by the metaphor of a stain (Greek miasma, Latin infectio), that could spread corrupting influence either by means of direct contact or through the bad air emitted by putrefac-

\footnotetext{
${ }^{31}$ Ibid., 69-70.

${ }^{32}$ Commentary on Lev. 11.

${ }^{33}$ I thank Markham Geller for suggesting that I explore the history of Western notions of infection.

${ }^{34}$ These expressions frequently persist as "dead metaphors" in our modern lexicon. Referring to expressions such as "coldblooded," "melancholy," and "hysterical," D. Wootton remarks, "Our language is littered with the flotsam and jetsam of a vast historical catastrophe, the collapse of ancient medicine, which has left us with half-understood turns of phrase that we continue to use because metaphorical habits have an extraordinary capacity for endurance" (Bad Medicine: Doctors Doing Harm Since Hippocrates [Oxford, 2006], 12).

${ }^{35}$ V. Nutton, "The Seeds of Disease: An Explanation of Contagion and Infection from the Greeks to the Renaissance," Medical History 27 (1983): 2.
}

tion (Greek sepsis). ${ }^{36}$ These two models for infection persisted as late as the mid-nineteenth century C.E., represented by the rival schools of contagionism (via direct contact) and miasmatism (via bad air) which attempted to account for the spread of cholera in London. ${ }^{37}$ In fact, these models - based on an assumed correlation between perceptible means of transmission and the spread of infection-severely impeded the emergence of alternative accounts, including the correct one, that cholera was transmitted by imperceptible water-borne germs. ${ }^{38}$

The important point that emerges from this brief historical survey is that we must be careful not to impose anachronistic category distinctions on the evidence, such as that between "religious pollution" and infectious disease. For example, upon noting that Greek notions of pollution could be dependent on the social status of a person, Eireann Marshall comments: "[W]hile ancient Greeks did not necessarily perceive diseases as infectious, they thought that religious pollution could be spread to other people." ${ }^{39}$ In a similar vein, the social historian Virginia Smith writes:

Religious purity has a distinct role in the history of personal hygiene. It was not functional, not rational, and more often than not completely illusory; but it was a key cultural component that determined the lives and cleansing behaviour of very large numbers of people. ${ }^{40}$

These authors would have been wiser to downplay such modern distinctions, as does Robert Parker in his more fitting characterization:

It is not clear that diseases ever truly became infectious in any other sense than this in Greek thought. Greeks were practically aware, in time of plague, that the disease could be contracted

${ }^{36}$ O. Temkin, "An Historical Analysis of the Concept of Infection," The Double Face of Janus and Other Essays in the History of Medicine (Baltimore, 1977 [1953]), 157, 161.

${ }^{37}$ See H. ten Have, "Knowledge and Practice in European Medicine: The Case of Infectious Diseases," in The Growth of Medical Knowledge, ed. H. ten Have et al. (Netherlands, 1990), 15-40.

${ }^{38}$ This case of scientific stagnation is all the more disturbing in light of the fact that the existence of micro-organisms had been observed by microscopes already in the late seventeenth century; see Wootten, Bad Medicine, 195-210.

39 "Death and Disease in Cyrene," in Death and Disease in the Ancient City, ed. V. M. Hope and E. Marshall (London, 2000), 22 (emphasis added).

${ }^{40}$ V. Smith, Clean: A History of Personal Hygiene and Purity (Oxford, 2007), 29-30. 
by contact, but in popular perception this may have been no more than an acute instance of the contagiousness of misfortune. ${ }^{41}$

For an accurate emic understanding of the ancient sources, it is not sufficient merely to recognize that the conflation of the categories "infection" and "defilement" is an inevitable consequence of the non-existence of a developed scientific approach for studying infectious disease. A full appreciation must acknowledge the existence of metaphysical schemes which assume dynamics such as the contagiousness of misfortune to be ontologically real. In rejecting the view that contagion beliefs are bizarre and counterintuitive, Nemeroff and Rozin make a similar point in stating:

It seems more plausible to us that the general set of invisible, insensible forces that can cause illness, death, disaster, and social effects might constitute a cognitive domain with its own relevant set of rules and principles-such as contagion, which deals with situations where things are not as they seem, where there is more to the eye than the obvious, and where imperceptible, transmissible forces exert their influences. ${ }^{42}$

In other words, contagion attitudes involve metaphysical assumptions, culture-specific understandings of invisible causal forces.

As has been elucidated in several recent studies, ${ }^{43}$ the epistolary evidence from Mari of the early eighteenth century в.C. provides us with the earliest written documentation of how the spread of infection was perceived. These letters describe the epidemic(s) which took place during the reigns of Zimri-Lim and Iasmah-Adad as a form of divine intervention. In these texts, a plague was referred to as a "devouring by the god" (ukulti ilim) or as the god's "placing the hand" (qātum šaknat) or "touching" (ilappat/ulappat) the affected region. These letters also describe the re-

${ }^{41}$ See Parker, Miasma, 219-20.

42 "The Makings of the Magical Mind," 25.

${ }^{43}$ J.-M. Durand, "Trois études de Mari," MARI 3 (1984): 143-49 (\$I/9. Maladies); E. Neufeld, “The Earliest Document of a Case of Contagious Disease in Mesopotamia (Mari Tablet ARM X, 129)," JANES 18 (1986): 53-66; W. Farber, "How to Marry a Disease: Epidemics, Contagion, and a Magic Ritual against the 'Hand of a Ghost'," in Magic and Rationality in Ancient Near Eastern and Greco-Roman Medicine, ed. H. F. J. Horstmanshoff and M. Stol (Leiden, 2004), 119-22. On contagious disease in general, see J. Scurlock and B. Andersen, Diagnoses in Assyrian and Babylonian Medicine (Chicago, 2005), 17-20. sponse to these plagues, which range from containing individual cases through quarantine to mass exodus from affected (laptum, literally "touched") cities.

Though the epidemics were attributed to divine anger, the descriptions of quarantine procedures resemble a fairly modern reaction to infectious disease. In a letter from the queen Šibtum to Zimri-Lim, it is related that her servant was placed in an isolated dwelling where she would eat her meals separately from the rest of the palace servants: "[No o]ne will approach her bed or chair." ${ }^{44}$ In a letter from ZimriLim to Šibtum, the king expresses concern regarding another infected servant who has been freely interacting with the personnel: "Now command that no one will drink from a cup that she drinks from, nor sit in a chair in which she sits, nor sleep on a bed in which she sleeps!"45

Scholars have noted that these sources find a striking parallel in Tablet III of the Mesopotamian Šurpu incantation which deals with the dangers of making contact with an "accursed" (tamî) person (lines $130-33):{ }^{46}$

the māmitu of talking to an accursed man, the māmitu of eating an accursed man's food, the $m \bar{a} m \bar{t} t u$ of drinking an accursed man's water, the māmitu of drinking an accursed man's left-overs.

Though the term māmittu originally signified an "oath-curse," it is depicted here as a curse that can be transferred through contact with the cursed person. ${ }^{47}$ As can be seen from the comparison with the Mari letters, the contagiousness of a curse was indistinguishable from that of a sickness. It is worth add-

${ }^{44}$ ARM 10, 14; Durand, "Trois études de Mari," 144; Farber, "How to Marry a Disease," 122.

${ }^{45}$ ARM 10, 129; Durand, "Trois études de Mari," 144; Farber, "How to Marry a Disease," 122.

${ }^{46}$ Text and translation: E. Reiner, Šurpu. A Collection of Sumerian and Akkadian Incantations, AoF Beiheft 11 (Osnabrück, 1970), 22-23 (with adaptations). For a synopsis of alternative readings, see R. Borger, "Šurpu II, III, IV, und VIII in 'Partitur'," in Wisdom Gods and Literature: Studies in Assyriology in Honor of W. G. Lambert, ed. A. R. George and I. L. Finkel (Winona Lake, IN , 2000), 48-49. The resemblance of this text to a notion of infection was observed already by H. E. Sigrist, A History of Medicine, vol. 1 (New York, 1951), 446. See also M. J. Geller, "The Šurpu Incantations and Lev. V. 1-5," JSS 25 (1980): 188; Farber, "How to Marry a Disease," 126.

${ }^{47}$ See Y. Feder, "The Mechanics of Retribution in Hittite, Mesopotamian and Biblical Texts," JANER 10 (2010): 127-35. 
ing that elsewhere we find numerous texts portraying māmìtu as an illness that must be treated by ritualistic medical means. ${ }^{48}$

These sources are highly relevant for understanding biblical notions of disease and defilement. First of all, like the usage of the Akkadian verb lapātu, the Bible employs the verbal root $n-y^{-}$( (whose basic sense is "to touch") to describe disease. The derivatives of this verb include the pielverbal form used to describe God afflicting people and lands with disease (e.g., Genesis 12:17; 2 Kings 15:5) and the nominal form nega', used to describe illnesses, especially the skin disease sara' $a t .{ }^{49}$ Second, like the Mesopotamian sources, the Bible refers to mass afflictions as manifestations of the "hand" of God. ${ }^{50}$ It is important to stress that these semantic parallels, as opposed to etymological ones, do not imply inter-cultural contact or influence, but rather the independent emergence of similar conceptions in both cultures.

A similar blurring of boundaries between divine punishment and pathological conditions is reflected in David's curse of Joab for the unjustified killing of Avner:

When David heard afterwards, he said, "I and my kingdom will be forever clean before the LORD of the blood of Avner the son of Ner. May it fall on the head of Joab and all of his kinsman. May there never cease to be in the house of Joab a gonorrheic, leper, a holder of the spindle, a victim of the sword or a person lacking bread (2 Samuel 3:28-29).

Among the other unenviable conditions mentioned in this passage, this curse refers to the gonorrheic and the leper ${ }^{51}$ who are among the most severe impurity bear-

${ }^{48}$ See CAD M/I 194; S. M. Maul, "Die 'Lösung vom Bann': Überlegungen zu altorientalischen Konzeptionen von Krankheit und Heilkunst," in Magic and Rationality, ed. Horstmanoff and Stol, 79-95.

${ }^{49}$ This parallel is noted by J. Milgrom (Leviticus 1-16, 776), though his interpretation that this term implies either a demonic attack or "contact with the pagan sphere" (following K. Elliger, Leviticus, HAT (Tübingen, 1966], 180) is unwarranted and contradicts his subsequent statement: "In the Bible, God is always the author of nega'." In $\mathrm{P}$ and $\mathrm{D}$, this term is used exclusively in reference to "leprosy."

${ }^{50}$ E.g., Exod. 9:3; 1 Sam. 5:6, 9; 2 Sam. 24:14-15. A comparable idiom $\left(y d^{\prime}{ }^{\prime}\right.$ ilm $)$ is also attested in Ugaritic texts (e.g., CAT $2.1011-13)$.

51 "Leprosy" is the conventional translations for the biblical term sara' $a t$, which seems to conflate several different types of skin diseases (see Milgrom, Leviticus 1-16, 816-20). ers commanded to bring a sin-offering in Leviticus 13-15 (see below). This source explicitly depicts these conditions as divine punishments. ${ }^{52}$ If we compare the contagious nature of divine punishment as manifested in the Mesopotamian sources cited above, especially the "curses" described in the Šurpu incantations, we may suspect that the stipulations pertaining to the transfer of "pollution" (tum'ah) in Leviticus 13-15 may be rooted in a concern that such pathological conditions may be contagious.

\section{Reassessing the Biblical Evidence: Between Infection and Pollution}

The previous sections have provided the theoretical and historical background for an embodied account of the biblical concept of pollution, particularly as it relates to infection. The first example to be discussed is Leviticus 15, which deals specifically with gonorrheics (zab; vv. 3-15), ${ }^{53}$ seminal emissions (16-18), menstruants (19-24), and female gonorrheics (25-30). Aside from stipulating the periods of separation and rites of purification necessary in the different cases, the chapter describes the manner by which pollution was spread, thereby revealing the ontological assumptions underlying the ritual prescriptions.

Throughout this chapter, one finds a repeated distinction between a severe degree of defilement requiring bathing and laundering and a lesser degree of defilement requiring only bathing. The following are cases of the severe form. Those pertaining to gonorrheics included: one who touched the gonorrheic's bedding (v. 5); one who sat in the gonorrheic's seat (6); one who touched his "flesh" (7, see discussion below); a person spat upon by the gonorrheic (8); one who lifted the gonorrheic's riding seat and other seating implements(?) (10b); and whoever the gonorrheic touched with unwashed hands (11). Regarding defilement by semen, laundering is required for any fabric or leather with semen on it (17). Severe defilement

\footnotetext{
${ }^{52}$ See S. M. Olyan, Disability in the Hebrew Bible: Interpreting Mental and Physical Differences (Cambridge, 2008), 54-56; Y. Feder, Blood Expiation in Hittite and Biblical Ritual: Origins, Context and Meaning (Atlanta, 2011), 107-108.

${ }^{53}$ The identification of the biblical condition with gonorrhea is only provisional. Nevertheless, it is worth noting that, against some claims to the contrary (e.g., Milgrom, Leviticus 1-16, 907), there is no reason to deny the awareness of venereal diseases in the ancient Near East. See now Scurlock and Andersen, Diagnoses in Assyrian and Babylonian Medicine, 88-97.
} 
by menstruants was transferred to one who touched their bedding or seats (21-22), and so too regarding the bedding or seats of female gonorrheics (26-27).

Although many exegetes assume that the person experiencing the discharge would bear the most severe degree of impurity, ${ }^{54}$ this assumption was at odds with the text. Throughout this chapter, we observe that people who suffered from prolonged genital emissions conveyed a degree of defilement by means of their sitting and laying on implements which was equivalent to or more severe than the defilement caused by touching the defiling person himself (see below). Clearly, the rationale for these laws was the entirely concrete concern that the emission would drip on the furnishings, so that the unsuspecting person who sat or lay on them might accidently touch the emission itself. In this regard, defilement operated as a "judgment heuristic," 55 whereby the mere possibility that an emission may have dripped on the object became a foregone conclusion, at least from the standpoint of preventing the further transfer of defilement. It is thus comparable to the repulsion from putting shoes on the kitchen table due to the fear that perhaps the person stepped in something objectionable. According to the logic of the heuristic, this possibility demands a behavioral response which takes it as a certainty. ${ }^{56} \mathrm{~A}$ similar heuristic is well-attested in ethnographic data, as reflected by the common fear of a menstruant stepping over one's food. ${ }^{57}$

So far, so good. We will now proceed to see how some purported difficulties in the text can be overcome by following this same logic. In particular, commentators have pointed out the discrepancy between the rule that touching the bedding or seat of female menstruants or gonorrheics required laundering (vv. 21-22;26-27) and the rule that contact with the discharger herself demanded only bathing (19, cf. 25).

\footnotetext{
${ }^{54}$ This assumption is fundamental to the rabbinic understanding of these laws, as well as that of D. Wright and J. Milgrom among modern commentators (see below).

${ }^{55}$ For a treatment of contagion as a heuristic (an emotionallybiased rule of thumb), see Rozin and Nemeroff, "Sympathetic Magical Thinking," 201-16.

56 The Samaritan halakba recognizes that the danger of direct contact with the defiling fluids is central to understanding purity laws and elaborates on this point in some detail. See I. R. Bóid, Principles of Samaritan Halachah (Leiden, 1989), 141, 148, 15051, 154; T. Kazen, "Explaining Discrepancies in the Purity Laws on Discharges," RB (2007): 362.

${ }^{57}$ See e.g., A. S. Meigs, Food, Sex, and Pollution: A New Guinea Religion (New Brunswick, 1984), 102-103.
}

Some commentators apply a fortiori logic to resolve the tension: if these implements, defiled by secondary contact, required laundering, then so much more so the discharger herself, the source of the impurity. ${ }^{58}$ Though this argument is perfectly logical, it misconstrues the rationale of the contagion schema by which the possibility of touching the discharge itself was of greater concern than touching the person.

But we must also consider the seemingly anomalous case of touching the "flesh" of the gonorrheic (7), which did require laundering and washing: "The one who touches the flesh (basar) of a gonorrheic will launder his clothes, wash and be impure until the evening." Here the problem surrounds the polyvalent term basar which was used in two distinct senses within the chapter: in the sense of "body" (vv. 13, 16) and as a euphemism for the male (vv. 2-3, 3x) and female (19) genitalia. Most commentators read the verse in the former sense such that any contact with the gonorrheic's body required laundering. ${ }^{59}$ Once again, some employ a fortiori logic: if touching the menstruant's body defiled (19), did it not stand to reason that touching the more severe gonorrheic also defiled? ${ }^{60}$

However logical this argument may have been, it is difficult to reconcile with the language of v. 7. First, we should note that basar in the sense "body" appears only in the context of washing, whereas the euphemistic sense appears in the context of defiling contact, as in the present verse. Second, all of the other cases which required laundering involved situations which put the person at risk of touching the emission itself. The only exception was the spit of the gonorrheic (8), which was still a form of direct contact with the impurity bearer's bodily fluid. Indeed, as noted above,

\footnotetext{
${ }^{58}$ So already the Rabbis: Sifra, Zabim, Par. 4:9 (ed. I. M. Weiss, Sipra with Rabad's Commentary [New York, 1946], 76a); m. Zabim 5:6. See also D. P. Wright, The Disposal of Impurity: Elimination Rites in the Bible and in Hittite and Mesopotamian Literature (Atlanta, 1987), 189.

${ }^{59}$ Ibn Ezra; G. J. Wenham, The Book of Leviticus, NICOT (Grand Rapids, MI, 1979), 219; Wright, Disposal of Impurity, 183; Milgrom, Leviticus 1-16, 914; Kazen, "Purity Laws on Discharges," 358 .

${ }^{60}$ Wright, Disposal of Impurity, 181, 183, n. 34. Milgrom attributes a similar deduction to the Rabbis, but I was unable to find the midrash cited (Leviticus 1-16,914). In any case, this understanding leads Milgrom to prefer the reading בה in v. 27 (along with 2 MSS and LXX) against the MT and other versions (943). However, since the structure of vv. 26-27 follows that of 21-22, MT should be retained.
} 
contact with the menstruant only required bathing (19b), a comparison which supports understanding basar in the more stringent law of v. 7 as referring to the gonorrheic's genitalia. ${ }^{61}$

Moreover, this interpretation is necessary to account for the stipulation in v. 11 that anyone whom the gonorrheic touched without washing his hands would have to launder and bathe. According to the understanding of v. 7 that any contact with the gonorrheic's body required laundering, one faces the difficulty to explain why the text specifically refers to his unwashed hands. However, the localized defilement of this verse is quite understandable if we assume that the concern was that his discharge may have defiled his hands. ${ }^{62}$ Since men touch their genitals when urinating, we can understand why this stipulation is not mentioned regarding female dischargers. ${ }^{63}$

As a result, we must understand v. 7 as referring to direct contact with the genitals of the gonorrheic. Though one may be initially surprised that the law would deal with such a possibility, it should be pointed out that the chapter deals elsewhere with defilement through sexual relations (18), including those with a menstruant (24). ${ }^{64}$ Unlike the (minor) defilement caused by ejaculation, which takes place only in the course of the sexual act, the discharge of the gonorrheic is continuous. Thus, even aside from sexual relations, contact with the gonorrheic's penis demanded laundering.

This line of interpretation allows us to offer a more precise explanation for the requirement of laundering. This requirement is often taken to be a merely formal indication of the distinction between severe and less severe forms of defilement. ${ }^{65}$ However, in light of the fact that the situations which demanded laundering involved potential contact with the emission itself, it would appear that the underlying concern was that the discharge may also have gotten on the person's

${ }^{61}$ A. Ehrlich, Randglossen zur hebräischen Bibel, vol. 2 (Leipzig, 1909), 52; Elliger, Leviticus, 191, 197.

${ }^{62}$ So the Samaritan "Book of Insight" (Boid, Principles, 145, 219).

${ }^{63}$ Wright, Disposal of Impurity, 183, n. 35; Kazen, "Purity Laws on Discharges," 363.

${ }^{64}$ This is the most severe case mentioned in the chapter, transferring a week-long state of impurity equivalent to that of the menstruant herself.

${ }^{65}$ E.g., Milgrom, Leviticus 1-16, 913: "Touching the bedding of the $z \bar{a} b$ requires laundering because of the intensity of the impurity." clothing. ${ }^{66}$ Thus, this rule was essentially an extension of the same heuristic which construed the possibility of a "stain" as a foregone conclusion.

A similar dynamic is implied by the biblical depiction of corpse impurity. In particular, Numbers 19:1415 states that a corpse defiles objects found together with it in an enclosure ('ohel, literally a "tent"): "This is the instruction: In the event a person dies inside a tent, anyone who enters the tent and anyone inside the tent shall be impure for seven days. Any open vessel that does not have a lid fastened around it is impure." The underlying conception seems to have been that this defilement would spread like a gas. ${ }^{67}$ As B. A. Levine points out, this mode of pollution is particularly clear from the law of the open vessel in v. 15: "The operative principle is that the impurity present within the structure invades all of its interior air, or space, and only sealed vessels are protected." 68 This conceptualization seems to have shaped, at least in part, the rabbinic elaboration of these laws. The conceptualization of corpse impurity as a gas is evident in various principles, including the assumption that corpse impurity spread in all directions inside a tent and the notion that it tended to escape through openings, that "it is the nature of impurity to exit and not to enter." ${ }^{69}$ Why did corpse impurity spread like a gas within an enclosure, unlike the forms of defilement described in Leviticus 15, which required contact? The answer is simple: the spread of this form of defilement was modeled after the dissemination of the stench of a decomposing corpse.

A similar correlation between phenomenal experience (odor) and the conceptualization of death pollution is found in other cultures. For instance, classical sources from ancient Greece and Rome attest to the belief that the house in which a corpse was found required purification and should be marked with a pine

${ }^{66}$ However, intensity of contact may perhaps explain other cases of laundering which are not related to genital discharges (e.g., Lev. 11:39-40; 14:46-7). See Wright, Disposal of Impurity, 185-86, n. 39 .

${ }^{67}$ So J. Neusner, The Mishnaic System of Uncleanness: Its Context and History (vol. 22 of A History of the Mishnaic Law of Impurities; Leiden, 1977), 72.

${ }^{68}$ B. A. Levine, Numbers 1-20, AB (New York, 1993), 467.

${ }^{69}$ For a discussion of "realistic" aspects of the tannaitic characterization of corpse impurity, see V. Noam, "Ritual Impurity in Tannaitic Literature: Two Opposing Perspectives," Journal of Ancient Judaism 1 (2010): 81-86. 
or cypress branch on its entrance to warn outsiders. ${ }^{70}$ Unfortunately, these references tend to be anecdotal, precluding further analysis. Modern ethnographic evidence, however, provides striking parallels which bear directly on the biblical case. Note, for example, the custom of Indonesians to scrupulously seal all of the cracks in a coffin from the concern that death will be spread with the odors. Herz writes: "The reason [Indonesians] consider it so highly desirable that the putrefaction should take place in a sealed container is that the evil power which resides in the corpse and which is linked to the smells must not be allowed to escape and strike the living." 71 A comparable view is attested among the Cantonese who fear the "killing airs" (sat hei) emitted by the corpse, which are thought to permeate the house of the deceased. Watson cites a local informant who describes the danger that the killing airs-associated with the departing spirit of the deceased-will cling to mourners "like an invisible cloud." 72 These parallels reflect a similar conceptualization of the power of death to spread in a manner corresponding to sense experience.

A final example is that of the "leper" described in Leviticus 13-14. Leaving aside the vexed question of the medical identification of this disease, the ostracization of the leper is strongly reminiscent of measures taken to avoid the spread of infection:

The leper who has the affliction: his clothes shall be torn, his hair shall be disheveled, he shall cover his moustache and call out: 'Impure, impure!' He shall be impure for all of the days that the affliction is upon him. He is impure. He shall dwell alone. His dwelling shall be outside the camp (Leviticus 13:45-46).

${ }^{70}$ See Parker, Miasma, 35, 38; E. Marshall, "Death and Disease in Cyrene," 10; H. Lindsay, "Death-Pollution and Funerals in the City of Rome," in Death and Disease, ed. Hope and Marshall, 155, $166,169$.

${ }^{71}$ R. Herz, Death and the Right Hand, trans. R. and C. Needham (Aberdeen, 1960 [1907-1909]), 32.

${ }^{72}$ See J. L. Watson, "Of Flesh and Bones: The Management of Death Pollution in Cantonese Society," in Death and the Regeneration of Life, ed. M. Bloch and J. Parry (Cambridge, 1982), 155-86, esp. 158. It is interesting to note that the reentry of mourners into society is marked on the seventh day by a ceremony known as "putting on the red" (ch'uan hung), in which mourners exchange their white mourning garb with red, associated with life and luck (p. 165). The color symbolism here offers a suggestive parallel to the red heifer rite of Numbers 19, though we must keep in mind that color symbolism in general is much more pervasive and explicit in Cantonese culture than in ancient Israel.
Despite the fact that the text makes no allusion to the possibility of infection, the requirement that the leper warn others of his condition and his isolation from the camp suggests a fear of contagion. The banishment of the leper is mentioned several times in the Hebrew Bible (e.g., Numbers 5:2-5; 12:14; 2 Kings 7:3-10), including non-Priestly texts, and this would seem to reflect actual practice. Moreover, the requirement to cover the mustache (or upper lip) of the leper has been explained as reflecting the fear that he would spread his condition through his breath. ${ }^{73}$ This interpretation finds support among interpreters of the Second Temple Period who warned against being downwind of the leper, which correlates suggestively with the fact that actual leprosy (Hansen's disease) is contracted via the respiratory system. ${ }^{74}$

Moreover, the purifying leper was to perform an elimination rite in which the pollution was transferred to a bird and sent off into the open country. Although this rite took place after he had already healed (Leviticus 14:3), it is highly reminiscent of scapegoat rites carried out in cases of plague. ${ }^{75}$ Finally, even after the first stage of purification was performed and the purifying leper was permitted to re-enter the camp, he was still required to dwell outside his tent (14:8). This latter requirement has been understood, already by its early interpreters in the Second Temple Period, as implying that he would defile all that was inside an enclosure with him. ${ }^{76}$

It is significant that the leper and the gonorrheic were required to bring expiatory offerings, which was not the case with normal bodily discharges. The leper was required to bring a sin offering together with a burnt offering (Leviticus 14:19, 31), and the blood of a guilt offering was daubed on his right ear, thumb

${ }^{73}$ Ibn Ezra on v. 45; Milgrom, Leviticus 1-16, 805-806. In fact, the Temple Scroll (46:16-18) and the Rabbis (Leviticus Rabbah 16:3) show concern for being downwind from the "leper." See also Y. Feder, "The Polemic Regarding Skin Disease in 4QMMT," DSD 19 (2012): 69.

${ }^{74}$ The validity of this point depends on the assumption that sara'at (in biblical and later usage) included Hansen's disease among other conditions. For discussion, see Feder, "Polemic Regarding Skin Disease," 68-70.

${ }^{75}$ See K. Aartun, "Studien zum Gesetz über den grossen Versöhnungstag Lv 16 mit Varianten. Ein ritualgeschichtlicher Beitrag," Studia Theologica 34 (1980): 84-86; Wright, Disposal of Impurity, 45-57; 65-69.

${ }^{76}$ See J. Melkman, "Leprosy," EJ 11:36; Milgrom, Leviticus 1-16, 843; Maccoby, Ritual and Morality, 141-8; Feder, "Polemic Regarding Skin Disease," 60, 63. 
and big toe (12-14, 21-25). Similarly, both male and female gonorrheics were required to bring sin offerings (Leviticus 15:15, 30). The need for expiatory offerings in these cases was consistent with David's curse which explicitly referred to leprosy and gonorrhea as divine punishments (2 Samuel 3:29).

However, the peculiar fact is that Priestly sources tended to draw a clear distinction between disease and sin. For example, unlike non-Priestly sources which frequently depicted leprosy as a punishment (e.g., Numbers 12; 2 Kings 5:26-27; 2 Chronicles 26:1621), P makes no inference of this sort. ${ }^{77}$ Moreover, the rationales given in the sin offering instructions clearly distinguish between offerings brought on account of transgressions (Leviticus 4; 16; Numbers 15: 22-31) and those brought on account of impurities (Leviticus $12 ; 14-15)$. Whereas the sin offering in the former cases served to expiate sin and gain forgiveness, in the latter cases it merely removed defilement. ${ }^{78}$ This distinction would seem to differentiate P's perspective from the conflation of sin and disease implied by David's curse. On this background, the requirement that the leper and gonorrheic bring expiatory offerings (Leviticus 14-15) is best understood as reflecting the conservatism of cult practice.

Aside from distinguishing between pollution and sin, Priestly materials also seem to distinguish pollution from infection. It is striking that the priests play no role in healing the leper; the text limits their function to his purification after the condition has healed on its own (Leviticus 14:3). ${ }^{79}$ This tendency is particularly striking in H's redaction of the purity rules, which emphasized the fear of defiling the sanctuary, and implicitly rejected any inherent danger associated with these conditions. Indeed, the exhortation concluding Leviticus 15:31 warns: "You shall set apart the Israelites from their impurities lest they die in their impurities by defiling my Tabernacle that is among

77 J. S. Baden and C. R. Moss, "The Origins and Interpretation of șāra'at in Leviticus 13-14," Journal of Biblical Literature 130 (2011): 643-53.

${ }^{78}$ See R. Gane, Cult and Character. Purification Offerings, Day of Atonement, and Theodicy (Winona Lake, IN, 2005), 112-24.

${ }^{79}$ See Y. Kaufmann, The Religion of Israel, trans. M. Greenberg (Chicago, 1960), 107-108; Milgrom, Leviticus 1-16, 887-89; cf. B. A. Levine, In the Presence of the Lord (Leiden, 1974), 83-85. Interestingly, a similar tendency is also attested outside the Priestly materials, particularly in the story of Naaman's leprosy ( 2 Kgs. 5 ), in which the contraction of the disease by Gehazi is portrayed as a consequence of his disobedience to Elisha and not as an immediate result of contagion. them." $"{ }^{80}$ Likewise, another $\mathrm{H}$ passage bans severe impurity bearers due to the threat of contaminating the sacred camp (Numbers $5: 1-3):^{81}$

${ }^{1}$ The LORD spoke to Moses, saying: ${ }^{2}$ "Command the Israelites to remove from the camp anyone with leprosy or a discharge and anyone defiled by a corpse. ${ }^{3}$ Remove male and female alike; put them outside the camp so that they will not defile the camp where I reside in their midst.

Strikingly, this verse specifies the three types of pollution that are based on models of infection: the leper, the gonorrheic and corpse impurity. Through the explicit reference to the divine presence in the midst of the camp, this verse effectively restricts these types of defilement to the sacral domain. ${ }^{82}$ Similar warnings appear in relation to corpse impurity (Numbers 19:13, 20). ${ }^{83}$ In these statements, failure to purify is depicted as defiling God's sanctuary, revealing a consistent tendency of $\mathrm{H}$ to restrict the threat of pollution to the sacred domain.

In summary, the Priestly depiction of these conditions presents us with a paradox. On one hand, the characterization of the spread of pollution as well as the isolation and expiatory offerings required of the impurity bearer hint at an underlying concern with

\footnotetext{
${ }^{80}$ On the ascription of this verse to $\mathrm{H}$, see Milgrom, Leviticus 1-16, 946-47; I. Knohl, The Sanctuary of Silence: The Priestly Torah and the Holiness School (Winona Lake, IN, 2007), 69-70. As these authors note, the first person possessive form משכני is a tell-tale indicator of H's authorship.

${ }^{81}$ As other commentators have pointed out, it is necessary here to distinguish $\mathrm{H}$ from $\mathrm{P}$, as Lev. 15 does not imply the banishment of the gonorrheic from the camp. See Milgrom, Leviticus 1-16, 920. A similar distinction can also be made regarding corpse impurity through comparison with Num. 19 (ibid., 276-77).

82 This straight-forward reading of the passage has been obscured by interpreters, ancient and modern, who interpret מחניהם as referring to "their camps" (plural) and thus assert the existence of a requirement to maintain purity in all cities. For a coherent understanding of the syntax and content of this passage, it is necessary to understand the form as singular ("their camp"). Note the form מחנך alongside Deut. 23:15, both meaning "your camp" (singular). Among the moderns, the fact that מחניהם in our verse is singular has been noted by J. Licht (A Commentary on the Book of Numbers, vol. 1 [Jerusalem, 1985], 59-60 [Heb.]), and Levine (Numbers 1-20, 182, 186), and it is assumed by the JPS translation. I plan on elaborating on these points in a study in progress, "The Wilderness Camp Paradigm in the Holiness Source and the Temple Scroll: From Purity Laws to Cult Politics."

${ }^{83}$ For the ascription of vv. 13, 20 to H, see Knohl, Sanctuary of Silence, 92-94.
} 
the spread of infection or curse. On the other hand, the biblical materials display an effort to de-emphasize or even deny the danger of infection. Despite these efforts to recontextualize pollution as posing a threat only in relation to the sacred domain, the behaviors associated with these forms of impurity indicate that these conditions were not always perceived to be innocuous.

\section{Pollution as Conceptual Scheme: Its Psychological Foundations}

Although the notion of an unseen force exhibiting physical properties may seem obscure initially, its inner logic can be revealed by reference to the cognitive linguistic notion of "conceptual integration." Unlike work on "conceptual metaphor" (e.g., "an argument is a war") that assumes a unidirectional mapping from a concrete source domain to a more abstract target domain, ${ }^{84}$ research on conceptual integration focuses on how two distinct domains can merge or blend. One type of conceptual integration which is particularly relevant to our discussion is that of experiential correlation, as elucidated through the theory of "primary metaphors." According to this theory, the inherent correlation between two or more units of experience (sub-scenes) in a recurrent primary scene can serve as the basis for primary metaphors. ${ }^{85}$ For example, a statement such as "You saw the logic of my argument" can be taken as based on a metaphor: "seeing is understanding." In this case, the primary metaphor "seeing is understanding" originates in the fact that the state of understanding (a cognitive sub-scene) often correlates with visual recognition (a perceptive sub-scene). In such situations, to visually detect $\mathrm{X}$ is tantamount to becoming aware of $\mathrm{X}$.

This analytic framework can be adapted to elucidate the biblical notion of blood-guilt, which is depicted

\footnotetext{
${ }^{84}$ For a brief introduction to this theory and its application to biblical studies, see J. Jindo, "Toward a Poetics of the Biblical Mind: Language, Culture and Cognition", VT 59 (2009): 222-43.

${ }^{85}$ See J. Grady and C. Johnson, "Converging Evidence for the Notions of Subscene and Primary Scene," in Metaphor and Metonymy in Comparison and Contrast, ed. R. Dirven and R. Pörings (Berlin, 2003), 533-55. For "primary metaphors" as a source of conceptual integration, see J. Grady, "Primary Metaphors as Inputs to Conceptual Integration," Journal of Pragmatics 37 (2005): 1595-1614. Many of the examples, including those below, could also potentially be described as metonymy-based metaphor, specifically the "effect for cause" metonymy (but cf. Grady and Johnson, “Converging Evidence," 540).
}

in numerous passages as a source of pollution (e.g., Numbers 35:33-34; Deuteronomy 21:1-9). The biblical corpus gives abundant expression to the view that the spilling of innocent blood results in a stain that would provoke a divine punishment on the entire community unless proper action was taken against the murderer. While some sources depict a personified conception in which the blood of the victim remains in a state of distress as long as the perpetrator goes unpunished (Genesis 4:11; Job 16:18), ${ }^{86}$ most sources depict retribution as an automatic mechanical process in which references to "blood" (damim) denote an invisible taint which threatens to invite punishment until the blood-debt is paid off. ${ }^{87}$ The important point for our purposes is that the guilt was conceptualized as a blood-stain, which could stain the perpetrator's body and pollute the land. This synthesis can be represented as follows:

\begin{tabular}{|c|c|}
\hline experiential sub-scenes & $\begin{array}{r}\text { metaphysical } \\
\text { concept }\end{array}$ \\
\hline physical blood stain & \multirow{2}{*}{$\begin{array}{r}\text { blood guilt as an invisible } \\
\text { stain }\end{array}$} \\
\hline $\begin{array}{l}\text { culpability (causing } \\
\text { retribution) }\end{array}$ & \\
\hline
\end{tabular}

Though one might be tempted to say that the blood symbolizes (i.e., represents) the culpability, this formulation distorts the fact that we are dealing with a single concept. In this case, the blood spilled is merely the perceptible aspect of a deed which has unseen, yet nevertheless inevitable, ramifications.

This phenomenon of conceptual integration is also manifested in the characterization of sexual misdeeds (especially incest) as polluting. ${ }^{88}$ As in the case of bloodshed, the guilt entailed by illicit sexual intercourse is depicted as defiling, a taint that can cause the land to vomit out its inhabitants (Leviticus 18: 26-28). The exceptional nature of these two categories of moral transgression-murder and sexual misconduct-has already been pointed out by Ricoeur in a cross-cultural generalization: "The comparison

${ }^{86}$ See also Isa. 26:21; Ezek. 24:7-8. This scheme should probably be related to the belief that the blood contains a person's animating spirit (e.g., Gen. 9:4; Deut. 12:23).

${ }^{87}$ E.g., Deut. 21:1-9; 2 Sam. 3:28; 21:1-6; 1 Kgs. 2:33. See Y. Feder, "The Mechanics of Retribution," 138-49, and Blood Expiation, 173-89.

${ }^{88}$ E.g., Gen. 34:5, 13, 27; Lev. 18; Num. 5:12-31. See FrymerKensky, "Pollution, Purification and Purgation," 408. 
Table 1

\begin{tabular}{|c|c|c|c|}
\hline Experiential Image & Uncleanness & Infection & Stain of transgression \\
\hline Core Emotion & Disgust $^{89}$ & Fear & Outrage $^{90}$ \\
\hline Examples & Normal genital discharges & $\begin{array}{l}\text { Abnormal genital discharges, } \\
\text { corpse impurity, leprosy }\end{array}$ & $\begin{array}{l}\text { Blood-guilt } \\
\text { Sexual immorality }\end{array}$ \\
\hline $\begin{array}{l}\text { Normative implications/ } \\
\text { concerns }\end{array}$ & Separation from sacred & Spread of misfortune & $\begin{array}{l}\text { Defilement of person/land, } \\
\text { divine retribution }\end{array}$ \\
\hline Methods of purification & Passage of time, washing ${ }^{91}$ & $\begin{array}{l}\text { Banishment, passage of time, } \\
\text { washing and sacrifice }\end{array}$ & $\begin{array}{l}\text { Expiatory act (if possible), } \\
\text { punishment }\end{array}$ \\
\hline
\end{tabular}

between sexuality and murder is supported by the same play of images: in both cases, impurity is connected with the presence of a material 'something' that transmits itself by contact and contagion." $" 92$

Similarly, we can depict the Israelite conception of pollution as it applies to genital disorders (Leviticus 15 ) as follows:

\begin{tabular}{|c|c|}
\hline experiential sub-scenes & $\begin{array}{r}\text { metaphysical } \\
\text { concept }\end{array}$ \\
\hline $\begin{array}{l}\text { physical stain of abnormal } \\
\text { discharges }\end{array}$ & pollution (tum'ah) spread \\
\hline $\begin{array}{l}\text { spread of misfortune } \\
\text { (infection) }\end{array}$ & through contact \\
\hline
\end{tabular}

A similar model could be used for corpse impurity (Numbers 19), but in this case, the correlation would be between the odor of the corpse and the perceived spread of misfortune.

We can now integrate these insights in identifying a set of base images of tum'ah in the Hebrew Bible. These separate models involve a clear correspondence between an experiential image and the emotional response and normative cultural implications involved with it. Though these models should not be taken rigidly (see my caveats below), they seem to reflect fundamental distinctions between different types of pollution (see table 1 ).

Forms of tum'ah which fit the broad characterization of being "unclean" are the least severe, requiring only that the person or object be distanced from the

89 "Disgust" as used here may vary from a mild sense of dirtiness following contact with semen to a more intense repulsion, e.g., as a reaction to menstrual blood.

${ }^{90}$ Cf. Kazen's reference to "sense of justice" ("Impurity, Ritual and Emotion").

${ }^{91}$ Regarding the sin offering of the parturient, see Feder, Blood Expiation, 141-42.

${ }^{92}$ Ricouer, Symbolism of Evil, 28. sacred realm. The governing factor here is the need to be pure when approaching God. ${ }^{93}$ This basic attitude towards approaching the divine realm is probably universal and finds vivid expression in the Mesopotamian concern not to approach the gods with even bad breath. ${ }^{94}$

The "infection" model has been discussed above at length. It pertains to a select group of conditions which were associated with a fear of contagion. This fear element can account for the more complex purificatory process and the need for sacrificial offerings. As noted above, the manner of infection is modeled after the concrete expression of this defilement (e.g., genital emission, odor).

The "stain of transgression" pertains to violations of cultural norms, specifically those of murder and sexual misconduct. Since these are analogous to the sources of infection in that they involve a release of bodily fluids (stains) and a fear of imminent danger (threats of punishment), the stain of transgression might be viewed as derivative of the cleanliness and infection models, which are more directly grounded in bodily experience. Unlike the other models, however, these forms of pollution are described as defiling the land, and they cannot be rectified by ritual cleansing or even sacrifice. These stains invariably lead to retribution: murder demands compensation for the blood spilled (expiation), and the perpetrators of sexual misdeeds will need to suffer divine punishment, such as the extirpation of one's lineage (karet). ${ }^{95}$

${ }^{93}$ See Lev. 12:4. This consideration is at work also in the law of the war camp in Deut. 23:10-15. Alongside the demand to exclude soldiers who experienced a seminal emission, the soldiers are required to relieve themselves outside the camp, so as not to offend the divine presence in their midst.

${ }^{94}$ See van der Toorn, Sin and Sanction, 21-36.

${ }^{95}$ Frymer-Kensky, "Pollution, Purification and Purgation," 406-409. To an extent, the distinction between bodily sources of pollution and the "stain of transgression" model resembles the distinction between "ritual" and "moral" impurity advocated by some scholars; see A. Büchler, Studies In Sin and Atonement in the 
As in the models analyzed by Nemeroff and Rozin, the distinct characteristics of each image, and particularly the distinct means of purification for each, supports the assumption that they were taken as separate models, despite the fact that they were incorporated into a common category: tum'ah. Although the relationship between these images and their role in the semantic development of tum'ah requires further study, it is possible, at least, to suggest a provisional assessment. I am inclined to view both the uncleanness and infection images as primary (i.e., not derived from one another), and subsequently merged under a single term. ${ }^{96}$ This convergence can be explained on the basis of the observation that contamination sensitivity is "elicitor neutral," as explained by Daniel Kelly: "Any elicitor of disgust, regardless of the actual nature of the elicitor or which 'domain' of disgust it falls in (physical, social, moral), has contamination potency of the same basic sort." ${ }^{97}$ That is to say, the notion of contagion was sufficiently generic to warrant the usage of a common term to describe both uncleanness and infection. ${ }^{98}$ However, as noted above, the stainof-transgression image should probably be viewed as a secondary development, modeled after aspects of uncleanness and infection. ${ }^{99}$

It should be stressed, however, that the biblical treatment of pollution in all of its heterogeneity captures a richness of embodied experience which cannot be adequately represented in a schematic chart.

Rabbinic Literature of the First Century (New York, 1967), 21269; J. Klawans, Impurity and Sin in Ancient Judaism (New York, 2000), 21-42. However, the schemas of pollution described here are closer to the Israelite conceptualization than the etic categories employed in modern scholarship.

${ }^{96}$ Interestingly, Kelly has advanced the "Entanglement Thesis," arguing that human notions of disgust are comprised of two evolutionarily distinct responses, the "affect program" which reacts to ingesting potentially toxic substances and "core disgust" which is an adaptive response to disease and parasites ( uuck! The Nature and Moral Significance of Disgust [Cambridge, MA, 2011], 43-60). Whether or not this theory is correct, it offers a suggestive model for how two similar but distinct experiences could converge under a common terminology.

${ }^{97}$ Ibid., 19; see also 33-34, 39.

${ }^{98}$ Hence, "pollution" should be viewed as a "classifier," a linguistically constructed category which can refer to several distinct types of experience (see Violi, Meaning and Experience, 132).

${ }^{99}$ The same would apply to the usage of pollution terminology to describe idolatry, which is further removed from bodily experience. For discussion of the latter, see Frymer-Kensky, "Pollution, Purification and Purgation," 406; André, "טמא," TDOT 5:330-31; Wright, "Unclean and Clean," 734.
In particular, it is not possible to determine a priority between the experiential schema and the emotion evoked by it. As noted above, emotional response is an inherent part of the perception of contagion. ${ }^{100}$ Furthermore, some sources of pollution do not conform so neatly to this analytic framework. In particular, though menstrual and puerperal blood are normal discharges, they had implications even outside the sacral sphere, namely in the strict ban on sexual relations. ${ }^{101}$ Since sex with a menstruant involves the violation of the acceptable norms of conduct, being listed together with abominable sexual acts such as bestiality and incest, and entails divine punishment (Leviticus $18: 19,20: 18)$, it fits the stain-of-transgression model in this regard. The severe ramifications entailed in the case of sex with a menstruant apparently stems from the extreme repulsion felt towards this behavior. ${ }^{102}$ But rather than contradicting the existence of distinct types suggested above, this case should serve as a reminder that the various types of pollution are ultimately derived from attitudes towards the body in all of its multifarious possibilities - not from a rigid disembodied logic.

\section{Conclusion}

In this paper, I have attempted to elucidate the embodied logic of pollution as depicted in the Hebrew

${ }^{100}$ This is a complex topic which requires further discussion. For the view that normative and affective content is built into concepts and schemas, see R. G. D'Andrade, "Schemas as Motivation," in Human Motives and Cultural Models, ed. R. G. D'Andrade and C. Strauss (Cambridge, 1992), 23-44; R. A. Shweder, "Ghostbusters in Anthropology," ibid., 45-58; P. Violi, "Beyond the Body: Towards a Full Embodied Semiosis," in Body, Language and Mind. Volume 2: Sociocultural Situatedness, ed. R. M. Frank et al. (Berlin, 2008), 66-71.

${ }^{101}$ For discussion of the "menstrual taboo" in Israel and crossculturally, see Eilberg-Schwartz, The Savage in Judaism; Malul, Knowledge, Control and Sex, 379-94; and more generally Meigs, Food, Sex, and Pollution; see also T. Buckley and A. Gottlieb, "A Critical Appraisal of Theories of Menstrual Symbolism," in Blood Magic: The Anthropology of Menstruation, ed. T. Buckley and A. Gottlieb (Berkeley, 1988), 3-53.

${ }^{102}$ A psychoanalytic interpretation suggests itself in light of the recognition that "disgust is antithetical to sexual desire" and that "disgust sensitivity is negatively correlated with the desire to engage in a variety of sexual behaviors," (D. M. T. Fessler and C. D. Navarrete, "Domain Specific Variation in Disgust Sensitivity Across the Menstrual Cycle," Evolution and Human Behavior 24 [2003]: 407), namely that the repulsion felt towards sex with the menstruant derives its intensity from the need to counteract sexual attraction. 
Bible. Contrary to the dominant tendency to search for a unified abstract logic which underlies the purity laws, I have aimed to show that these rules were based on a series of distinct models of contagion, including uncleanness, infection and the stain of bloodshed and sexual misdeeds. These models were based on schemas of recurrent human experiences and involved a correlation between a perceptible phenomenon (stain, odor, etc.) and an unseen essence (pollution). In particular, I have focused on the laws of abnormal genital discharges in Leviticus 15, corpse impurity in Numbers 19, and leprosy in Leviticus 13-14, all of which were based in folk conceptions of infection. Through surveys of philological, ethnographic and historical evidence, I have shown that similar models are attested cross-culturally throughout the ancient and modern worlds.

This exploration into the concept of pollution has important implications for the study of ancient Israelite thought. Earlier research has ascribed to the Israelites a "synthetic view of life" according to which they did not clearly distinguish between an action and its consequences. ${ }^{103}$ However, in light of recent studies focusing on the interdependency of mind, body, language and culture, we can offer a more precise formulation of this phenomenon and its cognitive basis. On the one hand, it is clearly insufficient to characterize the usage of "blood" (damim) as merely a case of linguistic polysemy, whereby the term can refer to either the physical substance or blood-guilt. Usage of the linguistic term is expressive of a unified experiential image which involves both perceived and hidden aspects of blood, such that the linguistic

${ }^{103}$ See e.g., K. Koch, "Gibt es ein Vergeltungsdogma im AT," ZTK 52 (1955): 1-42, referring to the earlier work of K. Fahlgren; G. von Rad, Old Testament Theology, vol. 1, trans. D. M. G. Stalker (Louisville, 2001 [1962]), 265; cf. J. S. Kaminsky, Corporate Responsibility in the Hebrew Bible (Sheffield, 1995), 26-28. concept serves as a reflection of the ontological assumptions of the ancient Israelite. On the other hand, instead of relying on a vague appeal to a purported ancient Israelite mentality, ${ }^{104}$ we must consider the possibility that this ontological belief is an inevitable consequence of semiotic circumstances, in this case the need to conceptualize the abstract notion (culpability) by means of a concrete image (blood). ${ }^{105}$ These two aspects could only be decoupled through the development of a linguistic terminology to distinguish them, though there was no reason to pursue such a terminology as long as they were perceived to be ontologically interrelated.

In comparison, the treatment of the concept of pollution indicates that it was ultimately distinguished from the notion of infection. In particular, H's redaction of the priestly instructions depicts these types of pollution as severe forms of uncleanness which were antithetical to the divine presence. If these genital discharges, leprosy and corpse pollution had originally evoked a fear of infection, the threat associated with them was now limited to the sacred camp (Leviticus 15:31; Numbers $5: 3 ; 19: 13,20)$. Though the profound ramifications of this reinterpretation of tum'ah are beyond the scope of this article, suffice it to say that although the physiological danger associated with this concept had been neutralized, its powerful socioreligious influence-as reflected in subsequent Jewish and Christian traditions-was only beginning to be manifested.

\footnotetext{
${ }^{104}$ For further discussion of the problem of "mentalities," see S. J. Tambiah, Magic, Science, Religion and the Scope of Rationality (Cambridge, 1990), 84-104: B. Shore, Culture in Mind: Cognition, Culture and the Problem of Meaning (New York, 1996), 167-204.

${ }^{105}$ For a different view on the function of conceptual blending, cf. E. G. Slingerland, "Conceptual Blending, Somatic Marking and Normativity: A Case Example from Ancient Chinese," Cognitive Linguistics 16 (2005): 557-84.
} 
